\title{
Suitability of the spider mite Tetranychus evansi as prey for Phytoseiulus persimilis
}

\author{
G. J. de Moraes \& J. A. McMurtry \\ Division of Biological Control, Department of Entomology, University of California, Riverside, CA \\ 92521, USA
}

Keywords: Acari, Phytoseiidae, Tetranychidae, antifeedant

\begin{abstract}
Experiments conducted to evaluate the suitability of T. evansi as a source of food for P. persimilis revealed that the primary factor responsible for the low oviposition rate and survivorship of the predator when fed T. evansi was the low amount of food ingested. P. persimilis detected and initiated feeding on T. evansi equally as well as on T. urticae. However, a feeding depressant was apparently responsible for a longer time spent by $P$. persimilis feeding on eggs of $T$. evansi than on eggs of $T$. urticae. Eggs of the former prey were totally consumed only occasionally. The depressant effect influenced subsequent feeding on $T$. urticae, increasing the time required for consumption and the number of partially consumed eggs for at least 3 days.
\end{abstract}

\section{Introduction}

Tetranychus evansi Baker \& Pritchard (Acari: Tetranychidae) reaches high population levels annually on wild and cultivated solanaceous plants in several countries (de Moraes \& McMurtry, 1985). Although some natural enemies have been found associated with $T$. evansi (Humber et al,, 1981; de Moraes \& McMurtry, 1983; Moutia, 1958), only three brief reports refer to the effects of predators on this spider mite. Moutia (1958) studied the biology of Feltiella sp. (Diptera: Cecidomyiidae) using T. evansi as prey. De Moraes \& Lima (1983) studied the suitability of $T$. evansi as prey for $E u$ seius concordis (Chant) (Acari: Phytoseiidae). De Moraes \& McMurtry (in press) evaluated the potential of eight species of phytoseiid mites in the genera Amblyseius, Phytoseiulus, Phytoseius and Typhlodromus as predators of $T$. evansi. None of the phytoseiid species studied were effective predators of T. evansi; their oviposition and survivorship rates were very low on this prey.

The reason for the unsuitability of $T$. evansi for the phytoseiid predators tested is not known. De
Moraes \& McMurtry (1985) found no evidence of an allomone (Brown, 1968) in T. evansi that acted against Phytoseiulus persimilis Athias-Henriot. Other possible reasons for the unsuitability of $T$. evansi as prey could be its morpho-physiological characteristics or the excessive amount of webbing produced by $T$. evansi. The present study evaluates the first possibility with the predator $P$. persimilis.

\section{Methods and materials}

This study was conducted in a laboratory at $25 \pm 1{ }^{\circ} \mathrm{C}$ and $40 \pm 10 \% \mathrm{RH}$. All tests were conducted in arenas $(4 \times 4 \mathrm{~cm})$ of Lima bean (Phaseolus vulgaris L.) leaves whose borders were covered by a $1 \mathrm{~cm}$ wide strip of Cellucotton. The arenas were maintained on wet foam mats in stainless steel pans. A piece of black paper $(0.5 \times 1.5 \mathrm{~cm})$ was placed in the center of each arena to provide shelter for the predators.

The predators ( $P$. persimilis) used in this study were obtained from a laboratory colony which was initiated with individuals collected in Ventura,

Entomol. exp. appl. 40, 109-115 (1986).

(c) Dr W. Junk Publishers, Dordrecht. Printed in the Netherlands. 
California, USA (originally received from Chile via West Germany). The colony was maintained on eggs and larvae of Tetranychus pacificus McGregor. T. evansi was collected from nightshade (Solanum douglasii Dunal) plants on the campus of the University of California, Riverside. Tetranychus urticae (Koch), a favorable prey species that was used as a control, was obtained from a laboratory colony maintained on Lima bean plants. Predators used in all tests were confined in glass vials of $1.5-\mathrm{cm}$ diameter $\times 4.5-\mathrm{cm}$ high for $24 \mathrm{~h}$ prior to the start of the experiments. Twelve individuals were placed in each vial. No food was provided during this period, but water was supplied two to three times by wetting the filter paper discs which covered the ventilation holes in the caps of the vials.

Increase in fresh body weight of predators fed immobilized prey

The suitability of all prey stages was evaluated. Before testing the mobile stages, prey specimens were collected and placed in a freezer $\left(-15^{\circ} \mathrm{C}\right)$ for $24 \mathrm{~h}$. This process immobilized the prey, and thus precluded the production of webbing. Sixty eggs, 60 larvae or 20 protonymphs, deutonymphs or adults were then randomly scattered in each arena, except under the piece of black paper. The eggs used were laid within a $24 \mathrm{~h}$-period.

Two predators were placed in each of five arenas containing one stage of a prey species. Ca. 1 and $3 \mathrm{~h}$ later, any predators that had escaped were reintroduced into the arenas. A group of ten predators, also starved for $24 \mathrm{~h}$, was placed in a bean leaf arena (ca. $30 \mathrm{~cm}^{2}$ ) and left unfed to serve as a control. All predators were returned to the vials after $5 \mathrm{~h}$ and held in the freezer for 1 to $5 \mathrm{~h}$ before being weighed. Predators from each treatment were weighed together using a Cahn electrobalance. The weights were reported in terms of the total for eight individuals. If less than eight (which rarely occurred) or more than eight individuals were present in the arenas after the $5 \mathrm{~h}$ period, their weight was converted to micrograms per eight individuals. The experiment was repeated five times for each stage of both prey species.
Number of eggs fed upon and time spent feeding

Two different tests were conducted. In the first test, 60 eggs (laid within a $24 \mathrm{~h}$-period) of either $T$. evansi or T. urticae were uniformly distributed in six rows in each arena. In the second, 30 eggs of each prey species were placed in six rows in each half of the arena.

One starved predator was added to each arena and observed for $5 \mathrm{~h}$ to determine the number of eggs attacked, the number of eggs partially or totally consumed, and the time spent feeding on the eggs. The predators were then left in the arenas for 15 to $20 \mathrm{~h}$, after which the same observations were repeated after replenishing the arenas with eggs. Replenishment of eggs during the $5 \mathrm{~h}$ observation period was not done because of the relatively small size of the arena, great mobility of the predator and large number of eggs still available even at the end of the observation period.

\section{Carryover effect of reduced rate of food intake}

In the first test, 50 starved predators were isolated in gelatin capsules, each of which contained one recently laid egg of $T$. evansi. After $1 \mathrm{~h}$, the capsules were examined and the predators that had apparently consumed an egg (what required ca. $0.2 \mathrm{~h}$ ) were collected and placed in arenas containing 60 randomly scattered eggs of $T$. urticae.

In other tests, groups of 20 to 30 predators were maintained for 24 or $48 \mathrm{~h}$ in arenas containing a surplus number of $T$. evansi eggs. Predators were then isolated in arenas containing 60 eggs of $T . u r-$ ticae, and the time required to consume the first egg or to consume each of the first 3 eggs attacked, was recorded. Except when the predators were allowed to consume only one egg of $T$. evansi, the tests were repeated with the same predators on three consecutive days. After the first observation period, the predators were transferred to another arena, containing a surplus number of all stages of T. urticae, and held until the next day. The predators were then moved to new arenas, containing 60 T. urticae eggs, for observation.

The control treatment consisted of providing the predators with eggs of T. urticae for $24 \mathrm{~h}$ and then recording the time required to consume one egg of T. urticae on three consecutive days.

The volumes of eggs of both species were calcu- 
lated from their diameters measured under a microscope. The weights were obtained with a microbalance, for groups of ten eggs.

\section{Results}

Increase in fresh body weight of predators fed immobilized prey

The average weights of groups of eight adult female $P$. persimilis fed each stage of either $T$, evansi of $T$. urticae or unfed are shown in Table 1. The weights of predators associated with $T$. evansi did not differ significantly from unfed predators, except when the prey was in the larval stage. Predators associated with larvae of $T$. evansi were about $25 \%$ heavier than unfed predators. Predators fed any of the stages of T. urticae were 50 to $70 \%$ heav-

Table 1. Average weights $(\mu \mathrm{g})$ of groups of 8 adult $q \subsetneq$ of Phytoseiulus persimilis $(\mathrm{n}=5)$ unfed or associated with $T$. evansi or T. urticae for $5 \mathrm{~h}$. Predators starved for $24 \mathrm{~h}$ before starting the test.

\begin{tabular}{lrrr}
\hline $\begin{array}{l}\text { Prey } \\
\text { stage }\end{array}$ & Unfed & \multicolumn{2}{l}{ Prey species } \\
\cline { 2 - 4 } & & \multicolumn{1}{l}{ T. evansi } & T. urticae \\
\hline Egg & $108.2 \pm 13.2 \mathrm{a}$ & $111.7 \pm 8.3 \mathrm{a}$ & $156.3 \pm 17.5 \mathrm{~b}$ \\
Larva & $80.6 \pm 5.9 \mathrm{a}$ & $99.6 \pm 9.4 \mathrm{~b}$ & $120.2 \pm 20.6 \mathrm{c}$ \\
Protonymph & $89.8 \pm 16.6 \mathrm{a}$ & $93.2 \pm 15.9 \mathrm{a}$ & $127.8 \pm 11.7 \mathrm{~b}$ \\
Deutonymph & $98.0 \pm 18.6 \mathrm{a}$ & $99.2 \pm 10.7 \mathrm{a}$ & $147.0 \pm 12.0 \mathrm{~b}$ \\
Adult ${ }^{\circ}$ & $81.2 \pm 5.9 \mathrm{a}$ & $88.4 \pm 7.2 \mathrm{a}$ & $126.4 \pm 9.5 \mathrm{~b}$ \\
Adult $\odot$ & $82.2 \pm 5.6 \mathrm{a}$ & $81.8 \pm 10.4 \mathrm{a}$ & $143.8 \pm 10.7 \mathrm{~b}$ \\
\hline
\end{tabular}

In same row, averages followed by different letters differ significantly at $5 \%$ level (t-Test). ier than unfed predators. Thus, each predator increased its weight by about 5 to 7 micrograms when feeding on $T$. urticae during a $5 \mathrm{~h}$ period.

\section{Number of eggs fed upon and time spent feeding}

On the first day, the period of time between the introduction of the predator into the arenas and the attack of the first egg averaged $13.5 \pm 10.6$ min for predators associated with $T$. evansi and $20 \pm 18.7$ min for those associated with T. urticae. On the second day, this period was $99.8 \pm 77.8 \mathrm{~min}$ and $102.3 \pm 55.2 \mathrm{~min}$ for T. evansi and T. urticae, respectively. These values indicated considerable variation and no clear difference in the attraction of the predator to eggs of either prey species.

Table 2 shows the parameters related to the consumption of eggs of $T$. evansi or T. urticae, during 5 -h periods on 2 consecutive days, with only one prey species present in each arena. On the first day, the number of eggs of $T$. evansi attacked was about one third that of T. urticae. Eggs were considered attacked when the predator assumed the characteristic feeding position, i.e., the pedipalps were resting on the egg and the anterior legs were extended over it (Jackson \& Ford, 1973). The low number of eggs of $T$. evansi attacked was attributed to an apparent avoidance reaction by the predator to eggs encountered after attacking the first egg. Many eggs of $T$. evansi that had been attacked were not consumed. The predators often spent a few seconds in the feeding position by an egg of $T$. evansi, but then left without causing any visible damage. An egg was considered consumed whenever a depression of the chorion was noticed after the predator attack, indicating that at least some feeding had oc-

Table 2. Consumption of eggs of $T$. evansi and $T$. urticae by $P$. persimulis on 2 consecutive days. Only one prey species offered to each predator; $\mathrm{n}$ in parenthesis.

\begin{tabular}{|c|c|c|c|c|c|c|c|c|c|c|c|c|}
\hline \multirow[t]{2}{*}{ Parameters } & \multicolumn{6}{|l|}{ First day } & \multicolumn{6}{|l|}{ Second day } \\
\hline & T. evansi & & ${ }^{1} \mathrm{CV}$ & T. urticae & & $\mathrm{CV}$ & T. evansi & & $\mathrm{CV}$ & T. urticae & & $\mathrm{CV}$ \\
\hline No. eggs attacked & $2.8 \pm 1.1 \mathrm{a}$ & $(15)$ & 39 & $9.1 \pm 2.7 \mathrm{~b}$ & (16) & 30 & $2.1 \pm 1.1 \mathrm{a}$ & (7) & 52 & $5.1 \pm 0.9 b$ & $(10)$ & 18 \\
\hline No. eggs consumed & $1.7 \pm 1.3 \mathrm{a}$ & (15) & 76 & $9.1 \pm 2.7 \mathrm{~b}$ & $(16)$ & 30 & $1.4 \pm 1.3 \mathrm{a}$ & (7) & 93 & $5.1 \pm 0.9 \mathrm{~b}$ & $(10)$ & 18 \\
\hline Time (min) feeding/egg & $9.0 \pm 5.2 \mathrm{a}$ & (26) & 58 & $3.6 \pm 1.1 \mathrm{~b}$ & $(145)$ & 30 & $9.1 \pm 7.4 \mathrm{a}$ & (10) & 81 & $3.9 \pm 1.0 \mathrm{~b}$ & (51) & 26 \\
\hline Total time feeding in $5 \mathrm{~h}$ & $19.0 \pm 12.2 \mathrm{a}$ & (15) & 64 & $32.2 \pm 10.5 b$ & (16) & 33 & $14.4 \pm 18.7 \mathrm{a}$ & (7) & 130 & $19.9 \pm 5.7 \mathrm{a}$ & (10) & 29 \\
\hline
\end{tabular}

${ }^{1}$ Coefficient of variation $(\%)$.

For each day, averages followed by different letters in same row are significantly different at $5 \%$ level ( $t$-Test). 
curred. The number of eggs of $T$. evansi killed by the predator was higher than the number consumed, as piercing the chorion and feeding for only a few seconds resulted in the eventual collapse of an egg. Eggs of T. urticae were attacked in series of three to eight, with searching intervals of 1 to 10 min between each egg. Generally, several of these feeding episodes occurred during the 5 -h period. The number of eggs of $T$. urticae consumed was the same as the number of eggs attacked, the only visible remains being the empty chorions.

Although $P$. persimilis attacked and consumed considerably fewer eggs of $T$. evansi than of $T$. urticae, the time spent feeding on each egg of $T$. evansi was longer. Eggs partially or totally consumed were considered in calculating of this parameter (Table 2). When the calculation was based on the five eggs of $T$. evansi that had been totally consumed on the first day, the feeding time per egg varied from 13.2 to $23.4 \mathrm{~min}$. In some cases, a predator consumed most of the initial T. evansi egg attacked, but very little of each of the eggs subsequently attacked. Only two of 145 eggs of T. urticae fed upon were only partially consumed. Accordingly, the coefficients of variation of the parameters measured (except for the number of eggs attacked) were ca. 2 times higher with $T$. evansi than with T. urticae.

The pattern of feeding observed on the second day was similar to that observed on the first day, except that the number of eggs attacked, number of eggs consumed, and total time spent feeding were somewhat lower, especially in relation to T. urticae. The lower values were attributed to the fact that the predators were not starved, but had been feeding since the test started on the previous day. Moreover, feeding on T. urticae eggs on the second day generally occurred in a single episode averaging $30 \pm 7$ min $(n=10)$ during the 5 -h period, rather than in several distinct episodes. Satiation occurred when 4 to 6 T. urticae eggs had been consumed. Only 1 of 51 eggs of T. urticae was partially, instead of totally consumed. No egg of $T$. evansi was totally consumed. The coefficients of variation of the parameters for the second day were higher than for the first day when the prey was $T$. evansi, but slightly lower when it was $T$. urticae.

The eggs of the two prey species differed both in size and weight. The average volumes of 100 eggs of T. evansi and T. urticae were $(12.5 \pm 1.2) 10^{-7}$ and (9.4 \pm 1.1$) 10^{-7} \mathrm{~cm}^{3}$, respectively. The average weights of ten groups of ten eggs were (13.1 \pm 0.6$)$ $10^{-6}$ and $(9.5 \pm 0.5) 10^{-6} \mathrm{~g}$, for $T$. evansi and T. urticae, respectively. These differences do not seem sufficient to explain the differences in prey attack and prey consumption by $P$. persimilis.

Table 3 shows the egg consumption by $P$. persimilis when both prey species were present in each arena. There were no significant differences neither between the number of eggs of each prey species attacked nor between the number of eggs of each prey species consumed. Some predators consumed relatively large numbers of eggs of $T$. urticae (ranges: $1-7$ on the first day, $0-5$ on the second day); whereas all predators consumed a relatively low number of $T$. evansi eggs $(0-3$ on the first and second days). The numbers of eggs of $T$. evansi consumed were lower than the numbers attacked, whereas the numbers of eggs of $T$. urticae attacked and consumed were the same on both days. The average time spent feeding on each egg was about the same on both prey species on the first day. On

Table 3. Consumption of eggs of $T$. evansi and $T$. urticae by $P$. persimilis on 2 consecutive days. Both prey species present in each arena; $\mathrm{n}$ in parenthesis.

\begin{tabular}{|c|c|c|c|c|c|c|c|c|c|c|c|c|}
\hline \multirow[t]{2}{*}{ Parameters } & \multicolumn{6}{|l|}{ First day } & \multicolumn{6}{|c|}{ Second day } \\
\hline & $T$. evansi & & ${ }^{1} \mathrm{CV}$ & T. urticae & & $\mathrm{CV}$ & T. evansi & & $\mathrm{CV}$ & T. urticae & & $\mathrm{CV}$ \\
\hline No. eggs attacked & $1.5 \pm 1.0 \mathrm{a}$ & (11) & 67 & $2.1 \pm 2.3 \mathrm{a}$ & (11) & 110 & $1.3 \pm 0.9 a$ & $(10)$ & 69 & $1.5 \pm 1.8 \mathrm{a}$ & $(10)$ & 120 \\
\hline No. eggs consumed & $0.9 \pm 0.9 \mathrm{a}$ & (11) & 100 & $2.1 \pm 2.3 \mathrm{a}$ & (11) & 110 & $0.8 \pm 0.8 \mathrm{a}$ & (10) & 100 & $1.5 \pm 1.8 \mathrm{a}$ & (10) & 120 \\
\hline Time (min) feeding/egg & $7.8 \pm 5.4 a$ & (10) & 70 & $4.4 \pm 2.7 \mathrm{a}$ & (23) & 62 & $7.5 \pm 3.3 a$ & $(8)$ & 44 & $11.4 \pm 7.7 \mathrm{a}$ & $(15)$ & 68 \\
\hline Total time feeding in $5 \mathrm{~h}$ & $7.9 \pm 8.6 a$ & (11) & 109 & $9.1 \pm 11.0 \mathrm{a}$ & (11) & 121 & $6.5 \pm 6.8 a$ & (10) & 105 & $17.1 \pm 23.4 a$ & (10) & 137 \\
\hline
\end{tabular}

1 Coefficient of variation $(\%)$.

t-Test, see Table 2. 
the second day, the feeding time on eggs of T. urticae was longer than that on $T$. evansi (although the difference was not statistically significant), because larger proportions of the contents of $T$. urticae eggs usually were consumed. In one case, a predator required $28 \mathrm{~min}$. to consume an egg of T. urticae. The total time spent feeding on prey eggs in $5 \mathrm{~h} \mathrm{did}$ not differ significantly between prey species on either day. However, some predators spent a long time (up to $62 \mathrm{~min}$ ) feeding on T. urticae eggs on the second day. The coefficients of variation were very high in relation to both prey species on both days.

For both prey species, the number of eggs attacked (Table 3) was similar to that when only $T$. evansi was offered (Table 2). The average time spent feeding on each egg of each species during the first day was similar to the feeding times when only eggs of the corresponding species of prey were available. However, on the second day, the average time spent feeding on each egg of $T$. urticae in the presence of both prey species was much longer than when only $T$. urticae was available. The total time (in $5 \mathrm{~h}$ ) spent feeding on $T$. evansi eggs averaged about half that when only this prey was available on both first and second days. However, the total time spent feeding on $T$. urticae eggs varied from the first to the second day. On the first day, the total time was only about a fourth of that when only T. urticae was present. On the second day, it was comparable to that when $T$. urticae was the only prey offered, because of a simultaneous decrease in the number of eggs consumed and increase in the time spent feeding on each egg.

The coefficients of variation were generally higher when both prey were offered in the same arena. This was particularly true with $T$. urticae, the coefficients of variation being two to six times larger than when it was the only prey available.

\section{Carryover effect of reduced rate of food intake}

Table 4 shows the effect of previous feeding on eggs of $T$. evansi on the time required by $P$. persimilis to completely consume the contents of each egg of T. urticae. Previous feeding on eggs of $T$. evansi resulted in a prolonged time required to consume eggs of T. urticae. Moreover, a large proportion of the $T$. urticae eggs attacked, were only partially consumed. This was rarely o'bserved when the predators fed only on T. urticae eggs. Partial consumption of $T$. urticae eggs was observed even when only one egg of T. evansi (ca. $0.2 \mathrm{~h}$ of feeding) was previously consumed, altholugh the effect was not as pronounced as when predators were confined with eggs of $T$. evansi for 24 , or $48 \mathrm{~h}$. After $24 \mathrm{~h}$ of confinement with $T$. evansi, feeding time on the first egg of $T$. urticae was longest. The average time required to consume the second and third eggs was significantly less thar that for the first. The time re-

Table 4. Time (min) required by $P$. persimilis to totally consume each egg of $T$. urticae as a ffected by previous feeding on eggs of T. evansi; $\mathrm{n}$ in parenthesis.

\begin{tabular}{|c|c|c|c|c|c|}
\hline \multirow{3}{*}{$\begin{array}{l}\text { Time (h) } \\
\text { feeding } \\
\text { previously }\end{array}$} & \multicolumn{5}{|c|}{ Days after treatments } \\
\hline & \multicolumn{3}{|l|}{ First Day } & \multirow[t]{2}{*}{ Second Day } & \multirow[t]{2}{*}{ Third Day } \\
\hline & 1st egg2 & 2nd egg & 3rd egg & & \\
\hline Ca. 0.2 & $\begin{array}{l}6.1 \pm 1.8 \mathrm{a} \\
(13)\end{array}$ & - & - & - & - \\
\hline 24 & $\begin{array}{l}15.9 \pm 4.0 \mathrm{Ab} \\
(21)\end{array}$ & $\begin{array}{l}9.1 \pm 1.9 \mathrm{~B} \\
(13)\end{array}$ & $\begin{array}{c}8.2 \pm 2.7 \mathrm{~B} \\
(13)\end{array}$ & $\begin{array}{c}5.3 \pm 1.9 \mathrm{Ca} \\
(30)\end{array}$ & $\begin{array}{c}4.0 \pm 1.5 \mathrm{Da} \\
(36)\end{array}$ \\
\hline 48 & $\begin{array}{c}12.7 \pm 4.8 \mathrm{Ab} \\
(8)\end{array}$ & - & - & $\begin{array}{l}5.5 \pm 1.7 \mathrm{Ba} \\
(11)\end{array}$ & $\begin{array}{l}3.0 \pm 1.1 \mathrm{Cb} \\
\text { (10) }\end{array}$ \\
\hline 24 (control) & $\begin{array}{l}2.5 \pm 0.7 \mathrm{Ac} \\
(35)\end{array}$ & - & - & $\begin{array}{c}2.5 \pm 0.9 \mathrm{Ab} \\
(30)\end{array}$ & $\begin{array}{c}1.7 \pm 0.7 \mathrm{Bc} \\
(15)\end{array}$ \\
\hline
\end{tabular}

\footnotetext{
${ }^{1}$ Always on eggs of $T$. evansi, except for control, where previous feeding was on $T$. urticae eggs; ${ }^{2}$ Order in which eggs were consumed.

Averages followed by different capital letters in same row or different lower case letters in same column differ significantly at $5 \%$ level (t-Test).
} 
quired to consume one egg on the second and third days was much shorter than on the first day, but still significantly longer than the control. Confinement of predators with $T$. evansi eggs for $48 \mathrm{~h}$ did not result in an increased time required for consumption of $T$. urticae eggs as compared to confinement for $24 \mathrm{~h}$. After the predators totally consumed an egg of T. urticae for the first time, partial consumption of an egg of the same species of prey occurred only occasionally.

The time required by control predators to consume one egg of T. urticae was about the same on the first and second days. For some unknown reason, it was significantly shorter on the third day. Similarly, a brief test indicated that $P$. persimilis required 4.6 $\pm 1.5 \quad(\mathrm{n}=21), 4.6 \pm 1.7 \quad(\mathrm{n}=15)$, and $3.4 \pm 1.2 \mathrm{~min}(\mathrm{n}=15)$ to consume each egg of $T$. pacificus, i.e., the same prey used for the stock colony, on 3 consecutive days, by utilizing the same setup. The time required to consume an egg on the third day was significantly shorter than that required on the first 2 days.

\section{Discussion}

De Moraes \& McMurtry (in press) obtained lower oviposition and survivorship rates with $P$. persimilis feeding on a combination of eggs, larvae and adult females of $T$. evansi, than on $T$. urticae. The results of the present study suggested that the performance of the predator on $T$. evansi is a result of low food intake. The low level of food intake was correlated with a low number of eggs attacked and consumed, a long time spent feeding on each egg, but a relatively short time feeding within the 5-h observation period. The level of food intake was much higher when the prey was $T$. urticae. The amount of food necessary for satiation of $P$. persimilis in this study was consistent with the data of Sabelis (1981), who reported that young $P$. persimilis females needed over $7 \mu \mathrm{g}$ of food (T. urticae eggs and adults) to become satiated after $24 \mathrm{~h}$ starvation at $25^{\circ} \mathrm{C}$. The same author determined that female $P$. persimilis had a handling time of 3.2 to $6.2 \mathrm{~min}$ when feeding on $T$. urticae eggs, and that the actual feeding period corresponded to $90 \%$ of the handling time. Thus, the feeding period of $P$. persimilis on T. urticae in this study is similar to that obtained by Sabelis (1981).
The higher coefficients of variation of the time spent feeding on each egg of T. urticae when both prey were available suggested a disturbing effect of the eggs of T. evansi on the consumption of eggs of T. urticae. This effect was variable, apparently because of the different numbers of eggs of $T$. evansi fed upon before a $T$. urticae egg was attacked.

The effect of impaired feeding on T. evansi was persistent, as a longer time was required to consume eggs of $T$. urticae that were subsequently attacked. However, this effect was significantly reduced after the consumption of the first egg of $T$. urticae. A possible explanation for the results obtained in this study is the presence of an antifeeding factor in $T$, evansi eggs. Slow elimination or inactivation of such an antifeedant (Ma, 1977) or a persisting central nervous system inhibitory state which decays after a time (Dethier et al., 1968; Jermy, 1971) could explain the time lag in the return to normal rate of consumption of $T$. urticae eggs. The longer time spent feeding on each egg of $T$. evansi suggested that the predator had difficulty in extracting the egg contents after piercing the chorion. This apparent difficulty also resulted in a number of eggs being only partially consumed. Akimov \& Starovir (1975) suggested that phytoseiids injected predigestive fluids in their prey for extra-intestinal digestion. Sabelis (1981) proposed that the different rates of food intake by $P$. persimilis on different stages of $T$. urticae resulted from different times required for extra-intestinal digestion. Such differences could also explain the longer time required by $P$. persimilis to consume eggs of $T$. evansi, but not the carryover effect which lasted up to 3 days. Based on the ideas of Dethier (1982) and Schoonhoven (1982), a possible explanation could be the presence of an antifeedant in $T$. evansi eggs that reversibly inhibits phagostimulant receptors (or stimulates antifeedant receptors) which would govern the injection of predigestive fluids into the prey.

De Moraes \& Lima (1983) observed that the oviposition and survivorship rates of Euseius concordis (Chant) were reduced when fed both T. evansi and a favorable prey, Aculops lycopersici (Massee), compared to the rates on $A$. lycopersici alone. The presence of $T$. evansi probably affected the consumption of $A$. lycopersici negatively in that study, although the authors attributed the effects to the excessive webbing of $T$. evansi.

In the absence of prey movement and webbing, 
the unsuitability of $T$. evansi as prey can be attributed either to the physico-morphological characteristics of this species (e.g., resistance of prey cuticle, ultrastructure or resistance of egg chorion) or to physiological effects. Scanning microscope observations in this study showed no major differences in the external appearance of $T$. evansi and T. urticae eggs. Also, no difference was noted in the efforts of the predator to penetrate $T$. evansi or T. urticae eggs. De Moraes \& McMurtry (1985) investigated the possibility of repellance of $P$. persimilis by $T$. evansi. Instead of repellance, the results showed arrestment of $P$. persimilis on filter paper discs treated with extracts of $T$. evansi. These findings and particularly the disturbance in the consumption of $T$. urticae eggs after $P$. persimilis fed on $T$. evansi eggs strongly suggest that $T$. evansi is physiologically unsuitable as prey for $P$. persimilis. Further studies are being conducted to evaluate the possible role of the host plant on the physiological suitability of the prey to the predator.

\section{Acknowledgements}

To R. D. Goeden and E. R. Oatman, Department of Entomology, University of California, Riverside, for the criticism.

\section{Résumé}

Adéquation de Tetranychus evansi comme proie pour Phytoseiulus persimilis

Les expériences d'évaluation de l'adéquation de $T$. evansi comme proie pour $P$. persimilis ont montré que le principal facteur responsable des faibles taux de ponte et de survie du prédateur alimenté sur $T$. evansi est la faible quantité d'aliments ingérés. $P$. persimilis avait découvert et commencé à s'alimenter sur $T$. evansi aussi bien que sur T. urticae. Cependant, un facteur réduisant la prise de nourriture a été responsable du temps plus important consacré à s'alimenter sur oeufs de $P$. persimilis que sur oeufs de T. urticae. Les oeufs de la première proie n'ont été que rarement consommés intégralement. Cet effet dépressif a influencé l'ali- mentation ultérieure sur T. urticae, en augmentant le temps nécessaire pour la consommation et le nombre d'oeufs partiellement utilisés au moins pendant les trois jours suivants.

\section{References}

Akimov, I. A. \& I. S. Starovir, 1978. Morpho-functional adaptation of the digestive system of three species of Phytoseiidae to predation. Dopovidi Akademia Nauk Ukrain SSR 7: $635-638$.

Brown, W. L., Jr., 1968. An hypothesis concerning the function of the metapleural glands in ants. Amer. Natur. 102: 188-191.

Dethier, V. G., 1982. Mechanism of host-plant recognition. Entomol. Exp. Appl. 31: 49-56.

Dethier, V. G., R. L. Solomon \& L. H. Turner, 1968. Central inhibition in the blowfly. J. Comp. Phys. Psych. 66: 144-150.

Humber, R. A., G. J. de Moraes \& J. M. Santos, 1981. Natural infection of Tetranychus evansi (Acarina: Tetranychidae) by a Triplosporium sp. (Zygomycetes: Entomophthorales) in northeastern Brazil. Entomophaga 26: 421-425.

Jackson, G. J. \& J. B. Ford, 1973. The feeding behaviour of Phytoseiulus persimilis (Acarina: Phytosenidae), particularly as affected by certain pesticides. Ann. appl. Biol. 75: $165-171$.

Jermy, T., 1971. Biological background and outlook of the antifeedant approach to insect control. Acta Phytopath. Acad. Scient. Hungaricae 6 (1-4): 253-260.

Ma, W. C., 1977. Alterations of chemoreceptor function in armyworm larvae (Spodoptera exempta) by a plant-derived sesquiterpenoid and by sulfhydryl reagents. Physiol. Entomol. 2: 199-207.

Moraes, G. J. de \& H. C. Lima, 1983. Biology of Euseius concordis (Chant) (Acarina: Phytoseiidae) a predator of the tomato russet mite. Acarologia 24: 251-255.

Moraes, G. J. de \& J. A. McMurtry, 1983. Phytoseiid mites (Acarina) of northeastern Brazil with descriptions of four new species. Intl. J. Acar. 9: 131-148.

Moraes, G. J. de \& A. McMurtry (1985). Chemically mediated aggregation of the predaceous mite Phytoseiulus persimilis to extracts of Tetranychus evansi and Tetranychus urticae. Exp. \& Appl. Acarol. 1: 127-138.

Moraes, G. J. de \& J. A. McMurtry (In press). Comparison of Tetranychus evansi and T. urticae (Acari: Tetranychidae) as prey for eight species of phytoseiid mites. Entomophaga.

Moutia, L. A., 1958. Contribution to the study of some phytophagous Acarina and their predators in Mauritius. Bull. Entomol. Res. 49: 59-75.

Sabelis, M. W., 1981. Biological control of two-spotted spider mite using phytoseiid predators. Part I. Modelling the predator-prey interaction at the individual level. Agricultural Research Report 910: 242 pp., Wageningen, The Netherlands.

Schoonhoven, L. M., 1982. Biological aspects of antifeedants. Entomol. Exp. Appl. 31: 57-69.

Accepted May 8, 1985. 